\title{
СОЦИАЛЬНО-ЭКОНОМИЧЕСКИЕ ИССЛЕДОВАНИЯ В АРКТИЧЕСКИХ РАЙОНАХ ЯКУТИИ В 6О-Е ГГ. ХХ В.
}

\section{SOCIO-ECONOMIC RESEARCH IN THE ARCTIC REGIONS OF YAKUTIA IN THE 1960S.}

\section{A. Suleymanov}

Summary: The article presents a pioneering attempt to generalize and comprehend research activities to develop the scientific foundations for the socio-economic development of the Arctic regions of Yakutia during the period of the beginning of active industrial development of the region. A provision has been formulated about the serious attention of representatives of the scientific community to a wide range of issues, including the conditions of life of the indigenous peoples of the North, various aspects of organizing the supply of the region, development and optimization of the transport system. It is noted that scientists at the same time took into account the interests of industrial enterprises and the local population, the number of which has sharply increased, primarily due to migration from the western regions of the Soviet Union. The mobilized materials allowed us to conclude that as a result of the implemented in the 1960s. Investigations identified a set of measures necessary to improve the quality of life and increase the effectiveness of socio-economic policy aimed at the development of the Arctic regions of Yakutia.

Keywords: Arctic, Yakutia, USSR Academy of Sciences, scientific research, traditional economy, industrial development.
$\mathrm{H}$ еуклонный рост значения обширных арктических пространств для экономики Российской Федерации актуализирует обращение к различным аспектам накопившегося в нашей стране векового опыта освоения северных территорий и акваторий, включая богатейшие традиции их научного познания. В данной работе представлена попытка реконструкции истории разработки научных основ социально-экономического развития арктических районов Якутии в 1960-е гг., осуществлявшейся силами сотрудников ведущего исследовательского центра Советского Союза - Академии наук (AH) CCCP.

Следует отметить, что указанное десятилетие в истории расположенных выше Северного полярного круга 13 арктических районов Якутии оказалось отмечено резкой активизацией его транспортно-промышленного освоения [10; 17]. В этот период здесь развернулась масштабная деятельность по поиску и разработке месторождений полезных ископаемых, приведших, в том числе, к появлению целого ряда новых населенных пунктов,
Сулейманов Александр Альбертович

К.и.н., С.н.С., Институт гуманитарных исследований и проблем малочисленных народов Севера Сибирского отделения РАН (2. Якутск) alexas1306@gmail.com

Аннотация: В статье представлена пионерная в отечественной историографии попытка обобщения и осмысления исследовательской деятельности по разработке научных основ социально-экономического развития арктических районов Якутии в период начала широкомасштабного индустриального освоения региона. Сформулировано положение о серьезном внимании представителей научного сообщества к широкому спектру вопросов, включая условия жизнедеятельности коренных народов Севера, различные аспекты организации снабжения региона, развития и оптимизации транспортной системы. Отмечено, что ученые при этом учитывали интересы промышленных предприятий и местного населения, численность которого резко возросла, В первую очередь, за счет миграции из западных регионов Советского Союза. Мобилизованные материалы позволили сделать вывод 0 том, что в результате осуществленных в 1960-е гг. изысканий был определен комплекс мер, необходимых для улучшения качества жизни и повышения эффективности социально-экономической политики, направленной на развитие арктических районов Якутии.

Ключевые слова: Арктика, Якутия, Академия наук СССР, научные исследования, традиционное хозяйство, индустриальное освоение. а также давших импульс развитию воздушного, речного и (в меньшей степени) автомобильного сообщения. Происходившие масштабные изменения, естественно, требовали соответствующего интеллектуального обеспечения. В течение 60-х гг. XX в. в Якутии появилось 2 новых академических института, а 3 уже функционировавших к началу интересующего нас десятилетия в его ходе значительно укрепили свой кадровой состав, расширили географию и тематику изысканий [1, с. 33-58; 13]. Одним из важных направлений исследований при этом стало определение ключевых проблемных точек и перспектив экономического развития Заполярной Якутии в меняющихся реалиях.

Наряду со своим познавательным потенциалом, а также обращению к востребованному в период реиндустриализации Российской Арктики и выработки новых подходов к ее освоению историческому опыту, анализ заявленной проблематики актуализирован текущей историографической ситуацией. Фактически единственным трудом, имеющим непосредственное отношение 
к проблеме изучения истории реализации социальноэкономических инициатив, посвященных вопросам развития арктических районов Якутии, к настоящему времени остается статья автора данной работы, в которой рассматривались изыскания участников Якутской северной комплексной экспедиции (ЯСКЭ) 1964-1965 гг. [16].

Источниковой основной для разработки заявленной темы, направленной на заполнение существующей историографической лакуны, послужили преимущественно документы, выявленные в Государственном архиве Российской Федерации (г. Москва), Архива Якутского научного центра СО РАН (г. Якутск) и его Рукописном фонде. Часть материалов при этом впервые вводится в научный оборот в данной статье. Второй условной группой стала научная литература, подготовленная участниками рассматриваемых изысканий по их итогам.

Конечно же, важнейшей социально-экономической научной инициативой рассматриваемого периода стала упомянутая ЯСКЭ. В связи с тем, что данной экспедиции, как отмечалось, была посвящена отдельная статья здесь представляется возможным лишь вкратце охарактеризовать проводившиеся в рамках нее исследования.

Якутская северная комплексная экспедиция стала первой и, к сожалению, остается единственной глубоко междисциплинарной социогуманитарной академической инициативой, участники которой охватили своими работами практически всю Заполярную Якутию - сразу 10 ее административных районов. В ходе осуществленных изысканий были получены сведения, характеризующие жилищно-бытовые и санитарно-гигиенические условия, состояние здоровья, сохранность элементов традиционной культуры, современный охват социально-культурным обслуживанием, семейные отношения, распределение гендерных ролей в среде коренных народов Севера, качество образования, оленеводство, скотоводство, коневодство, охотничий и рыболовный промыслы, транспортную систему, развитие горнодобывающей промышленности и ее влияние на уровень жизни местного населения и многое другое. Важнейшей целью данных исследований при этом было, как представляется, попытка побуждения союзных властей к пересмотру параметров господствовавшей в СССР ресурсной модели освоения северных пространств. Эта, цель тогда, к сожалению, достигнута не была [16].

Вместе с тем, помимо комплексных экспедиционных работ в 60-е гг. XX в. получили развитие также более локальные исследования. Так, в 1962 г. в арктических районах Якутии продолжил свои работы И.С. Гурвич, осуществлявший изыскания в регионе с начала 40-х гг. XX в. [9].

На этот раз начальник северо-восточного отряда Северной экспедиции Института этнографии им. Н.Н. Миклухо-Маклая (ИЭ) АН СССР проводил исследования в Оленекском и Нижнеколымском районах Якутии. Помощь в сборе эмпирического материала И.С. Гурвичу оказывал его ученик, аспирант ИЭ АН СССР Н.А. Алексеев.

Целью исследований было выяснение текущего социально-экономического положения представителей коренных народов Севера.

Проведенные изыскания показали, что в целом условия жизни представителей аборигенных этносов по сравнению с предыдущим десятилетием не стали лучше. Более того, в связи с реорганизацией колхозов в совхозы усугубилась проблема обеспечения местного населения привычным рационом питания (мясо и рыба), т.к. при новой форме коллективного хозяйствования труд оплачивался исключительно деньгами, натуральные же выдачи были полностью прекращены. Это привело к ситуации, при которой “потребление населением привычных традиционных национальных продуктов настолько сократилось...", что стало "вызывать серьезные опасения за существование коренного населения" [12, с. 266]. По сведениям И.С. Гурвича, раньше один мужчина употреблял в среднем 1,5-2 кг мяса в день, а нередко 3-4 кг. В 1962 г. же в Оленекском совхозе оленеводам отпускалось только 7 кг мяса по себестоимости (40-50 коп) на одного человека в месяц или 200-230 г в день. Охотники же получали еще меньше - 150 г. В итоге население было вынуждено покупать мясо по розничным ценам - 2 руб. 20 коп. за кг при среднем доходе 80-100 руб. Досадный парадокс ситуации заключался в том, что такие высокие цены были установлены правительством, чтобы поддержать оленеводческие колхозы и повысить уровень жизни аборигенных этносов.

Положение усугубляли недолов рыбы, практически полное исчезновение диких оленей - традиционного источника дополнительного пропитания северных народов, а также такой лимитирующий фактор развития, как фактическое отсутствие личных подсобных хозяйств. При этом даже эти, минимальные, объемы выловленной рыбы, а также недостающаяся работникам совхоза оленина шли на корм лисиц и песцов в звероводческие хозяйства, приносивших ежегодный убыток - И.С. Гурвичем был поставлен вопрос о нецелесообразности насаждения нетрадиционных видов хозяйствования (по крайней мере, в существовавших масштабах). Рекомендации, выработанные ученым, сводились к сокращению количества разводимых зверей до тех размеров, которые можно было бы прокормить за счет отходов. Это позволило бы освободить трудовые ресурсы, способные интенсифицировать оленеводство и охоту, а также сэкономить мясо, что могло дать возможность улучшить рацион питания представителей аборигенных этносов и сделало бы более эффективной дорогостоящую борьбу с туберкулезом [12, с. 266]. 
Рассмотренные материалы фактически резюмируют изыскания И.С. Гурвича, проведенные в арктических районах Якутии. Следует отметить, что в последующем подобные критически направленные оценки применительно к фундаментальным аспектам условий жизни аборигенных этносов региона автору данной работы удалось встретить только в исследованиях уже перестроечного периода. К сожалению, нет уверенности, что здесь сказалось, действительное улучшение социальноэкономического положения проживающих в регионе представителей коренных малочисленных народов Севера и комплементарный характер работ, в которых могли критиковаться лишь частности, обусловлен именно этим, а не другими факторами.

При этом, как свидетельствует выявленный источниковый материал, исследования И.С. Гурвича продолжали сохранять достаточно критическую позицию в оценке социально-экономической и этнокультурной ситуации среди аборигенных этносов Российской Арктики, которую он не стеснялся доводить до органов власти различного уровня. Так, по результатам экспедиционных исследований, проведенных в Шмидтовском районе Чукотского национального округа Магаданской области в 1975 г., ученый подготовил и направил в Совет Министров РСФСР докладную записку «К проблеме улучшения развития хозяйства, культуры и улучшения быта коренного населения Севера Чукотки». В документе, наряду с целым рядом положительных моментов (значительная доля молодежи, занятая в оленеводстве; высокий уровень трудоустройства; совместное кочевание семей; механизация труда; радиофикация бригад), резкой критике подверглась работы промышленных предприятий, в результате которой были загрязнены окрестные реки и морское побережье, сделавшее невозможным рыболовную и морзверобойную деятельность аборигенов; изыскания геологов и старателей привели к делихинизации, "обезжизниванию" значительных участков тундры, как в силу непосредственной добычи ресурсов, так и передвижения транспорта. И.С. Гурвич отметил, в частности, что промышленное освоение Севера не увязано с развитием традиционного промыслового хозяйства и "пока что ничего не дало коренному населению, а в ряде случаев способствовало ухудшению бытовых условий" $[11$, л. 9]. Ученый также выступил против намечавшегося продолжения политики поселкования, укрупнения населенных пунктов и ликвидации "неперспективных" сел как в виду необходимости сохранности этнокультурной компоненты и традиционного хозяйства чукчей, так и элементарной защиты от последствий неблагоприятных контактов с "цивилизацией" - алкоголизации и тунеядства. Не многим лучше, по сравнению с 50-ми гг. XX в., стала и ситуация в интернатах. Здесь были зафиксирована те же, что и ранее проблемы: скученность проживания, приводившая к быстрому распространению инфекций, отсутствие в рационе питания привычных для детей продуктов (мясо морского зверя, рыба), оторванность воспитательной работы от национальной культуры [11, л. 7-25].

Вернемся к исследованиям, проводившимся в арктических районах Якутии. В июне-июле 1966 г. Н.А. Алексеев продолжил свои полевые работы в регионе в рамках Северной экспедиции ИЭ АН СССР повторно посетив Оленекский, а также Булунский районы. Основной целью изысканий по-прежнему было выяснение условий жизни коренного населения. С этой целью исследователь изучил в Тикси материалы плановых и статистических районных управлений, характеризующие развитие сети учреждений образования и культуры, взял интервью у представителей руководящих органов и работников местных организаций. В Кюсюре и Харыялахе Н.А. Алексеев собрал сведения о хозяйственной деятельности, средних доходах работников, условиях оказания медицинских и образовательных услуг, особое внимание уделив школам-интернатам. Кроме того, в ходе исследований были записаны воспоминания старожилов о существовавших охотничьих обрядах, благосостоянии предков, методах их хозяйствования, традиционной одежде и жилище [14, л. 1-157; 15, л. 1-147].

Изыскания И.С. Гурвича и Н.А. Алексеева в общемто являлись логическим и проблемным продолжением работ, проводившихся в 50-е гг. XX в. Однако в 1960-е меняющиеся социально-экономические реалии в арктических районах Якутии, связанные с активным индустриальным освоением, которое сопровождалось резким увеличением притока населения, ставили перед исследователями новые задачи.

В частности, изучением проблемы снабжения растущего населения низовий Колымы свежим картофелем и другими овощами занимался сотрудник отдела экономики Якутского филиала Сибирского отделения (ЯФ СО) АН СССР Л.И. Щербаков. В подготовленном по данной теме в 1965 г. научном отчете были представлены сведения о завозе названной продукции в регион, ее себестоимости, сравнительные данные обеспеченности по населенным пунктам. Проведенные изыскания показали крайне низкую степень удовлетворения потребностей населения в овощах. Так, показатели потребления свежей продукции в год составляли всего лишь 5\% от необходимого. Для исправления положения исследователь предложил ряд мер. Прежде всего, он рекомендовал завозить в регион поздние сорта картофеля вместо более дорогих ранних. При этом требовалось жесткая выдержка графика отправок товара из Архангельска - не позднее начала сентября, чтобы успеть доставить картофель по Северному морскому пути. Кроме этого, Л.И. Щербаков предложил создать в Нижнеколымском районе тепличный комбинат с искусственным обогревом. По мнению ученого это должно было обеспечить население района свежими огурцами, редисом, укропом и др. Автор отчета произвел расчеты необходимой производственной мощности 
такого комбината, требуемых для его строительства и функционирования финансовых вложений, а также стоимости производимой продукции и ее доставки до потребителя [5, л. 1-18].

Еще одним направлением исследований экономистов Якутского филиала СО АН СССР в 60-е гг. XX в. было изучение вопросов лесоснабжения арктических районов Якутии. Социально-экономическое развитие региона привело также к значительному росту использования продукции лесной промышленности. Об этом и об острой нехватки местного сырья, убедительно свидетельствуют данные возросшего в течение 1958-1968 гг. практически в три раза объема завоза лесных грузов в порт Тикси [8, л. 62]. Важность поисков возможных путей оптимизации лесоснабжения арктических районов в таких изменившихся условиях, естественно, диктовали необходимость проведения соответствующих научных изысканий.

Работы по данной тематике проводил научный сотрудник отдела экономики ЯФ СО АН СССР Е.К. Цой. В 1967 г. он подготовил научный отчет, в котором рассматривались различные аспекты лесоснабжения населения и предприятий Нижнеколымского района. В работе ученый оценил объемы и направления поставок лесоматериалов (местный лес был непригоден для строительства) за 1965 г., проанализировал характер поступающей продукции. Так, было выяснено, что основной объем поставок составляет необработанная древесина. В то же время, по расчетам Е.К. Цоя, замена ее на готовые пиломатериалы или продукцию домостроения давала бы ежегодную экономию в 500 тыс. рублей. Основной причиной сложившегося положения исследователь назвал неразвитость деревообрабатывающей промышленности в Якутии, и в частности в ее юго-западных районах - основном источнике поставок на Нижнюю Колыму. Имелись недостатки и у готовой продукции, завозимой с дальневосточных портов - она, как правило, изготавливалась из ели и пихты, обладавших по сравнению с лиственничной и сосновой продукции, пониженными эксплуатационными свойствами. Решению проблемы должно было способствовать, по мнению автора, строительство Табагинского лесопильно-деревообрабатывающего комбината. Поставка готовой продукции из Якутска должна была дать экономию примерно в в 100 тыс. рублей. Кроме того, автор отчета рекомендовал организовать сплав древесины с верховьев Колымы [6, л. 1-5].

Другой серьезной проблемой, связанной с лесоснабжением Нижнеколымского района, Е.К. Цой назвал заготовку дров - значительная часть предприятий и населения по-прежнему использовали именно этот вид топлива. Между тем, трудности, возникавшие при их заготовке по всему северу Якутии, с каждым годом значительно возрастали - число деревьев в приемлемой близости от населенных пунктов неуклонно снижалось.
Не был исключением и Нижнеколымский район. Так, для обеспечения дровами предприятий и населения поселков Черский и Зеленый мыс уже приходилось производить лесозаготовки на расстоянии 60-70 км от этих населенных пунктов - более близкие леса уже были вырублены. Это, естественно, вело к повышению себестоимости заготовки дров и отвлечению дополнительных трудовых ресурсов (10\% работников совхоза “Нижне-Колымский" в 1965 г.). При этом, как справедливо замечал автор, дальнейшая вырубка могла привести к заболачиванию местности и исчезновению ценных промысловых видов животных. Единственным выходом из сложившегося положения Е.К. Цой назвал скорейший переход предприятий района на использование угля с развивающихся Зырянских месторождений [6, л. 5-8].

Немного позднее Е.К. Цой подготовил капитальный отчет по проблеме лесоснабжения всех северных районов Якутии, а также Магаданской области.

Основой разработки темы послужили экспедиционные работы, проведенные ученым, научная литература, материалы статистических управлений, научно-исследовательских учреждений, промышленных предприятий, строительных и транспортных организаций ЯАССР, Магаданской области, Приморского и Хабаровского краев.

Е.К. Цой произвел хозяйственную оценку лесосырьевого потенциала Якутии и Магаданской области. Проанализировав данные по запасам древесины, продуктивности лесов, преобладающим породам, их возрасту и эксплуатационным характеристикам, ученый, как и ранее в отчете по Нижней Колыме, пришел к выводу, что наиболее оптимальным с точки зрения экономической эффективности будет организация лесоснабжения исследуемого ареала из Олекминского и Ленского районов Якутии с обработкой в Якутске.

Одновременно исследователь оценил объемы и структуру потребления древесины в Абыйском, Аллаиховском, Анабарском, Булунском, Верхоянском, Жиганском, Момском, Оймяконском, Оленекском, Томпонском, Усть-Янском, Верхне-, Средне- и Нижнеколымском районах Якутии, а также в Магаданской области. Е.К. Цой проанализировал маршруты и состав поставок лесоматериалов. Это позволило автору найти возможные пути сокращения транспортных издержек, как за счет поставок обработанной продукции, а не круглого леса, так и оптимизации дальности пробега. Кроме того, Е.К. Цой определил перспективные потребности в лесоматериалах и продукции деревообработки исследуемого ареала.

Важное место в названных работах занимали авторские рекомендации по рационализации лесоснабжения северных районов Якутии и Магаданской области. Помимо замены ассортимента поставок на готовую 
продукцию и совершенствования схем доставки, они содержали предложения по строительству в наиболее перспективных районах (Ленск и Хандыга) крупных деревообрабатывающих комбинатов, более эффективного использования транспортных средств (за счет порожних рейсов Дальневосточного пароходства из Тикси, использования судов класса "река-море”) [8, л. 1-110].

В рассматриваемый период получили развитие также и исследования по вопросам развития транспортной системы Заполярной Якутии. В первую очередь они были связаны с именем коллеги Е.К. Цоя по отделу экономики ЯФ АН СССР Б.В. Белинского.

В 1964 г. он защитил кандидатскую диссертацию в области географических наук "Экономико-географические проблемы комплексного развития транспорта в Янском бассейне Якутской АССР" [2], в 1966 г. -подготовил научный отчет “К вопросу о завозе грузов на Индигирку и Колыму" [4], а также осуществил подробный анализ состояния авиаобслуживания населения бассейна реки Яны и транспортно-логистических перспектив этого региона $[3,7]$.

В названных работах ученый представил развернутую характеристику состояния путей сообщения, пассажиро- и грузоперевозок в арктических районах
Якутии, определил перспективные направления грузопотоков, оптимальные маршруты и сроки организации снабжения населения и промышленных предприятий региона той или иной продукцией. Одновременно Б.В. Белинский разработал подробные комплексные схемы оптимальных направлений транспортного освоения Северного Депутатского и Южного Янского промышленного ареалов. Изыскания ученого включали и выработку конкретных практических рекомендаций по снижению логистических издержек и улучшения транспортной доступности северо-восточных районов Якутии, повышения качества жизни местного населения.

\section{Зак^ючение}

Таким образом, значительная часть рассмотренных исследований, проведенных в арктических районах Якутии, была направлена на разработку научных основ социально-экономического развития региона, учитывающих как быстро трансформирующиеся реалии (активное транспортно-промышленное освоения, миграция населения), так и разноплановые интересы акторов этого процесса - горнодобывающих предприятий, аборигенного и недавно прибывшего населения. Осуществленные изыскания позволили определить комплекс мер, необходимых для улучшения качества жизни и оптимизации деятельности хозяйствующих субъектов.

\section{ЛИТЕРАТУРА}

1. Академическая наука в Якутии (1949-2009 гг.) / гл. ред. А.Ф. Сафронов, отв. ред. В.В. Шепелев. Новосибирск: Гео, 2009. 220 с.

2. Архив Якутского научного центра Сибирского отделения (АЯНЦ СО) СО РАН. Ф. 1. Оп. 4. Д. 241.

3. АЯНЦ СО РАН. Ф. 1. ОП. 4. Д. 252.

4. АЯНЦ СО РАН. Ф. 1. ОП. 4. Д. 259.

5. АЯНЦ СО РАН. Ф. 1. Оп. 4. Д. 263.

6. АЯНЦ СО РАН. Ф. 1. ОП. 4. Д. 278.

7. АЯНЦ СО РАН. Ф. 1. ОП. 4. Д. 296.

8. АЯНЦ СО РАН. Ф. 1. Оп. 4. Д. 307.

9. Батьянова Е.П., Жорницкая М.Я. Илья Самуилович Гурвич (1919-1992) // Этнографическое обозрение. 1992. № 5. С. 167-171.

10. Боякова С.И. Якутский сектор Арктики: опыт и уроки освоения // Исторический и политический опыт национальной государственности в России: региональные особенности. Материалы Всероссийской научной конференции с международным участием, посвященной 115-летию со дня рождения М.К. Аммосова и 90-летию образования ЯАССР. Якутск: СВФУ, 2013. С. 102-108.

11. Государственный архив Российской Федерации. Ф. 259. Оп. 46. Д. 5798.

12. Гурвич И.С. 0 положении коренного населения северных районов Якутской АССР // Этнологическая экспертиза: народы Севера России. 1959-1962 годы. М.: ИЭА РАН, 2005. С. 266-273.

13. Куперштох Н.А. Становление академической науки Якутии и ее вклад в изучение производительных сил северо-востока России // Якутский архив. 2012. № 1. С. 9-18.

14. Рукописный фонд Архива (РФА) ЯНЦ СО РАН. Ф. 5. 0п. 1. Д. 566.

15. РФА ЯНЦ СО РАН. Д. 567.

16. Сулейманов А.А. Якутская северная комплексная экспедиция 1964-1965 гг. // Научный диалог. 2019. № 11. С. $465-480$.

17. Элерт Э.Х., Тимошенко А.И. Россия в Арктике: проблемы изучения исторического опыта освоения региона // Гуманитарные науки в Сибири. 2016. № 3. C. $5-12$. 